MedieKultur | Journal of media and communication research | ISSN 1901-9726

Article - Theme section

\title{
(Big) Data, Diagram Aesthetics and the Question of Beauty
}

\section{Falk Heinrich}

MedieKultur 2016, 59, 73-94

Published by SMID | Society of Media researchers In Denmark | www.smid.dk The online version of this text can be found open access at www.mediekultur.dk

The article investigates whether and in what way artistic artefacts deploying big data can be experienced as beautiful. The question is relevant because the sentiment of beauty indicates not only an immediate sensory valuation but also changes in cultural values and epistemic frameworks. The article focuses on artistic data visualisations. It applies concepts of philosophical aesthetics in order to trace an altered notion of beauty and its artistic and cultural implications.

The article's introductory section presents some examples of data visualisations and introduces relevant notions of beauty and big data. The main part discusses changes in our concept of beauty by analysing data visualisation in the light of conceptual art and its aesthetics of the sublime. Data visualisations present potentially unfathomable and complex information that is associated with the sublime but represent data in a way that allows for understanding by means of imagination, which are aspects of beauty. The article explores the simultaneity of and oscillation between aesthetic beauty and the aesthetic sublime by introducing Deleuze's conceptual distinction between the diagram that is able to mediate between visualisation as representation and the diagram as performative machine of formation and displacement of data relations. 


\section{Introduction}

Big data and the aesthetics of art seem to be contradictory. Art is often seen as personal and eclectic, brought about by a single artist or a small group of artists. Big data, on the contrary, denotes a huge amount of information that is distilled into different descriptive categories in order to describe and prognosticate general traits or developments in various fields such as climate changes, migration patterns, internet user search patterns and much more. Big data treats humans as impersonal data sources that only have significance as a mass phenomenon. Art, however, is said to be concrete and particular. Nonetheless, there are works of art that include fairly large amounts of data in various and quite diverse ways': first, as pieces made up of graphic representations of data collections; second, as dynamic and sometimes also interactive installations making use of databases or the Internet as huge pools of fluctuating data; and, third, as conceptual works of art that thematically discuss the phenomenon of big data in one way or another.

Moreover, some of the data art pieces are difficult to categorise unmistakably as art. In one way or another, they either expand the field of art or position themselves in the grey zone between art and scientific data visualisation and engineering. I do not want to engage in this normative discussion but rather pragmatically include it all, because I am interested in the repercussions brought about by data in the field of aesthetics, whether the artefacts are categorised as art, artistic design or simply aesthetic artefact. For this investigation, the decisive factor seems to be neither the sheer amount of data nor what counts as art but the fact that the data employed describes or otherwise directly stems from real life occurrences and this in a very distinct way. Big data is most often a collection of descriptive data and meta-data that categorises the concrete incident or status (for a somewhat more thorough description of data, see next chapter). Big data appears to become an objectivized part of the work of art as a kind of incommensurable surplus that evades artistic construction and interpretation. In that, it has similarities with some strategies of various avant-garde movements (the historical avant-garde, the neo-avant-garde and, later, the performance art movement beginning in the 1980s) that sought to destroy art's representational paradigm by including everyday objects and the performer's privacy (for example, personal stories) on stage. The various avant-garde movements have changed our notion of art, our expectation of art (see, for example, Bürger (1984) or Burnham (1968)), and also our aesthetic taste for artistic interplays between presentations of incommensurable realities (especially, the simultaneity of fictitious and material reality, e.g., Fischer-Lichte (2008); Heinrich (2014)).

The article's basic question is: How does data art shape our notion of aesthetics or, in order to sharpen the question further: whether artistic (re)presentations of big data be experienced as beautiful and in what way? In answering this question, I will primarily be dealing with visual (re)presentations of big data -, not because I think this is the main artistic format for data art but because, historically, beauty has predominantly (rightly or not) been connected to visual and figural representations (the female body, painted or 
photographed nature, still lifes and so forth). It seems to be the most straightforward way path into the field of data art and the question of beauty (but I might be mistaken exactly because it emphasises the picture and prevents us from looking at beauty from a different perspective - for example, from the perspective of performativity and participation).

\section{Examples of Data Visualisation}

One example of so-called artistic data visualisation is Jer Thorp's work. His pieces often visualise selected data types and data flows of the Internet. The piece Wired UK 2010, for example, visualises specific parameters of phone calls made in the UK during a certain timespan. The piece is best described by its process of creation, which started out by filtering data. Thorp anonymised data about telephone calls made in Europe by choosing three meta-parameters: the individual caller and the number and the length of their calls. He represented the parameters by means of columns along $(x, y)$ axes, so that callers who talked for a long time are located close to the zero point of the $x$-axis, while other callers are located proportionally farther away. Within each column, long calls are rendered as yellow, short calls are rendered as red, and text messages are flat blue rectangles. The distribution of colours is determined by the data; however, they present aesthetic choices. Thorp produced several of these graphs and arranged them in a 3-dimensional space by grouping the zero points of the $y$-axes together, resulting in a star-like formation. Then, Thorp took the long straight $x$-axes and bent them several times in an irregular manner. A more organic shape emerged in which the $x$-axes are reminiscent of a long tentacle. The orange-yellow shapes look fairly dramatic against the black background.

Another comparable example is Tatiana Plakhova's work Jellyfish (2009), which visualises network relations by means of dots and lines that do not follow a scientifically-accepted diagrammatic order but are influenced by criteria normally associated with artistic endeavour in the sense of being guided by personal inspiration and associations. In the case of Plakhova's piece, the design of the visualised connection mimics a kind of jellyfish - hence, the title. These works do not display any avant-garde ambition whatsoever. What is interesting are their dual and seemingly contradictory qualities with regard to, firstly, measurable data and, secondly, as autonomous aesthetic artefacts. Both are meaningful in very distinct ways.

Many related projects exist - some exhibited in art galleries and museums, others in public institutions or urban spaces. Lynn Hershman's Synthia Stock Ticker (2000-02) and M. Hansen and B. Rubin's Listening Post (2003) serve as examples of the former, D-Tower in Doetinchem by Q.S. Serafijn and architect Lars Spuybroek / NOX-Architekten of the latter. Every one of these pieces connects the real (measurable) world with artistic objects/ events by means of data and thereby the pieces document the world. Other pieces refer to big data either thematically or functionally without necessarily deploying big data. The Most Wanted Painting (1994-97) by Komar and Melamid can here be seen as a forerunner 
because it uses a fairly large amount of data in its construction of best-liked paintings, a kind of sample on the basis of quantitative questionnaire results. However, the collected data and the resulting paintings directly allude to aesthetic taste in art and, therefore, can be read as a meta-comment on the modern abyss between artistic objectives and common taste. Recently, Lev Manovich has often worked with the three-dimensional visualisation of art historical data such as selected features of the paintings of one artist or a group of artists during a distinct art historical epoch (Manovich, 2015). Other pieces critically and humorously treat data as surveillance - for example, Rokeby's Taken (2002) or Marie Sester's Access (2003). Again, in this article, I want to focus on data visualisation because it allows me to trace more easily and to question philosophically the changing notion of aesthetics.

\section{Why is the Question of Beauty Relevant for Big Data Art?}

The question of beauty seems to be odd with respect to (big) data art because, on the face of it, the purpose of these artefacts appears to be something other than to be beautiful. As mentioned, there are many media art pieces that tap into online data repositories such as Internet traffic, data describing the weather, the stock market, etc. These data often serve as information that initiates systemic incidences of a kind (e.g., animated figures as in Hershman, Synthia Stock Ticker (2000) or bits of text as in Hansen and Rubin's Listening Post (2003)). Hence, other relevant artistic motivations might be questions such as whether and in what way big data can be the means and building blocks of artworks. In addition, criticism and artistic reflection on the personal, cultural and societal significance, danger and potential of big data and data surveillance are important artistic impulses.

However, these important questions by no means contradict the validity of this article's question concerning the beauty of data art. First, some types of artistic representations of big data clearly seem to stimulate our sense of visual beauty; there are several books on the beauty of data visualisation, most of them stemming from the field of design and data science (e.g., Steele and Iliinsky, 2010; Segaran and Hammerbacher, 2009). In this regard, Lev Manovich characterises data visualisation as an "anti-sublime ideal" because "data visualization artists aim at precisely the opposite: to map such phenomena into a representation whose scale is comparable to the scales of human perception and cognition." (Manovich, 2002) The anti-sublime ideal must consequently be the ideal of beauty. But does that mean that data visualisations intend aesthetic beauty as an autonomous category or are they, as Warren Sack notes, merely "an exercise in beautiful image making to render data 'friendly' or 'easy'" (Sack, 2011)? And is this a contradiction? Evidently, one can discuss whether the above-mentioned visualisations actually are beautiful, but surely they demand an aesthetic judgment simply because we immediately and perceptually react to framed ${ }^{2}$ graphical formations of lines and dots, which spur imagination, associations and appreciative understanding. Aesthetic judgment is the very foundation of the predominant concept of beauty. 
Second and most importantly, aesthetic beauty expresses cultural values through sensory tastes (see, for example, Hume, 1757/2008; Kant, 1764/2011; Sartwell, 2004). Thus, our sentiment and our question concerning beauty may also say something about the epistemological mechanisms of aesthetic presentations: the elements that contribute to human realisation in a given epoch. The specific question, therefore, is whether big data artefacts-be they visualisations, auditory artefacts or art installations--present or, more modestly, are expressions of changed aesthetic ideals (in a Hegelian sense) compared to, first, representational and figural art that relates to reality through artistic (interpretive) mimicry and, second, any form of abstract art that works with aesthetic expression of materials, forms and non-representational composition.

Artistic visualisations of big data are clearly not intended to be scientific diagrammatic presentations of data but to exercise a certain degree of artistic freedom. Yet, it is also clear that--in order to be visualisations--these artefacts, in one way or another, have to represent or refer to collections of data describing empirical world occurrences. This blurs the division between scientific and artistic (re)presentation more than it formerly may have been ${ }^{3}$ and surely has an influence on our notion of aesthetic judgment. Hence, a subsidiary question concerns the kind of interplay diagrammatic picturing brings about between sense perception, imagination and realisation. This question lies at the very heart of Baumgarten's aesthetics.

I shall briefly present my understanding of beauty and introduce the (non-) concept of big data.

\section{A Notion of Beauty}

As explained by, for example, Hume and Kant, aesthetic judgments in modernity are seen as subjective. ${ }^{4}$ They are intrinsically bound to one person and this person's preferences, knowledge about and experience with the object of the judgment (Hume). In the case of art, knowledge about and experience with art and even with specific art forms and genres will inevitably shape one's aesthetic judgment. Nevertheless, we experience our judgments as immediate perceptions of pleasure (or aversion).

Second, even though any aesthetic valuation is subjective and bound to one particular object (or event), its bearings are historical-cultural formations that frame our aesthetic judgment. That means that human aesthetic sensibility is variable and shaped by sociocultural changes. Expressed differently, our aesthetic judgment responds to socio-cultural, historically-fluctuating ideals that are expressed by artefacts. Our aesthetic judgment is, thus, not based on so-called generic artistic or aesthetic rules of, for example, composition, colour and semblance because such rules always express perceptual values of a well-defined historical art epoch (e.g., Neoclassicism). Other epochs developed other rules. Subjectivity may also be said to be one such rule, inextricably bound to the Enlightenment and Modernity. Hence, the amalgamation of socio-cultural elements (which include any sub-cultures) 
and individual preconditions shapes our aesthetic judgment that is experienced as pleasurable (or not). To explain this assertion in depth would exceed the scope of this paper--I elaborate on that in my book Performing Beauty in Participatory Art and Culture (2014).

My third premise is that each artistic form (every artefact that can be subsumed under the Greek term techne as a form of revealing (Heidegger, 1993)) can bring forth the sentiment of beauty by creating a unity between the artefact and the person perceiving/using/ interacting with this artefact. This can happen on various levels - for example, as a perceptual unity, an agential unity or a unity in terms of realisation. Beauty is sensed as pleasure that emerges out of this felt unity (Heinrich, 2014). I often use the term 'beautiful experiences' because beauty is tightly connected to the relationship and interaction between an artefact and the human (here, I am standing on the shoulders of Whitehead (1933/1969)). On the contrary, the expression 'the experience of beauty' indicates beauty as a metaphysical or transcendental idea that is an attribute of an object.

Finally, my fourth presupposition is that, in artistic domains, a reflective distance or, better, an observational distinction between the artefact and the perceiving person always accompanies and sometimes competes with this feeling of unity. This yields a second order observation of the perceiver's sense perception in relation to the very act of observing or interacting with an artefact in its contextual situatedness. That is why the sentiment of beauty (at least, in our culture) is a paradox that brings us closer to life by inserting an observational distinction. The feeling of unity is accompanied by alienation. My understanding of beauty always entails a dimension of longing (Heinrich, 2014), which is also expressed by Stendhal's famous proposition: "Beauty is the promise of happiness" (Stendhal, 1980). One cogent example from the representational arts might be Mora's painting The Artist in His Studio (1905), which depicts a nude model and the painter. The painter can only approach the model and her erotic beauty by painting her, thereby introducing a separation, a distinction that cannot be overcome but elicits the reflective dimension of beauty different from (but, nonetheless, connected to) enacted eroticism. The distinction opens up a second-order observation that is always informed by and based on cultural values and the prevailing episteme. Kant asserts that the judgment of beauty presumes the imagined agreement of all other persons in a society or community (sensus communis); in his earlier work on the feeling of the beautiful, he directly hints at existing cultural values of different cultures ${ }^{5}$ (Kant, 2011).

The sentiment of beauty is not only able to trace cultural values but, as a corollary, also changes to the existing epistemic framework. The beautiful experience of an aesthetic artefact says more about the status of an artefact within its cultural fabric - that is, about what and how we comprehend what we perceive of it - than about an artefact as an inherent entity. I will come back to this in connection with (big) data art. For the moment, this very rudimentary presentation of my understanding of beauty must suffice. Now, a closer look at the notion of big data is relevant for this investigation. 


\section{The (Non-)Concept of Big Data}

Big data is a fairly new term (especially in relation to the arts); it indicates a vast collection of data arrays and data samples stemming from a multitude of sources. The term 'big' indicates that the sheer amount of data requires extraordinary tools to extract usable knowledge. "Big data is high volume, high velocity, and/or high variety information assets that require new forms of processing to enable enhanced decision making, insight discovery and process optimization" (Laney, 2012). Big data connotes, in principle, unordered aggregates of data that promise some form of self-organisation. Some big data collections show selfconstituent and emergent meta-level networks on the basis of, for example, users' Internet behaviours or other dynamic data types (e.g., weather, geological transformation, pollution). Here, the occurrences traced seem directly to (in)form models and diagrammatic presentations that appear to evade human conceptualisation and scientific construction (see, for example, the discussion of Snijders et al. (2012) on power laws in regard to node behaviours). However, some scholars characterise this as the mythological aspect of big data (Boyd and Crawford, 2012, p. 663).

One popular and comprehensible example of big data and its possibilities is Google's swift identification of an influenza epidemic by looking at Google search queries of distinct terms as tokens of an incipient proliferation of the illness. Big data collections are used in different fields such as business, science and government. Research in and application of big data is a vast, growing field because it promises information that has not been obtainable until now, such as complex migration patterns, customer behaviour and climate change. Besides being a buzzword, big data can be seen as new grist for the positivist mill because accumulation and (self-)formation of data promise, first, to transcend subjective experiential and hermeneutic perspectives and, second, to allow for the emergence of hidden correlations from the similarity of patterns. However, it cannot be questioned that big data is the result of human interpretative agency.

Thus, big data provides big challenges: how to question the criteria by which the data are collected, how to filter data and how to extract usable information without a conceptual framework that paradoxically diminishes the possibilities for new realisations. The discussion concerning big data circles around the possibilities and pitfalls of huge aggregations of data and the expectation of more trustworthy presentations of states of affairs and models of actual and future developments. Truth is here epitomized as quantitatively-aggregated data that seem valid in distinct contexts and research fields. Big data, thus, seems to be more a research question than a well-defined term that encapsulates a concept with distinct features and demarcations.

Sense-making always requires interpretation on the basis of categories, filters and correlation principles, which, in principle, may yield new comprehensions that would not have been possible otherwise. Furthermore, the act of collecting data necessitates selection criteria that decide on what is collected and how. Manovich (2015) explains that data science (applied to art-historical investigations) entails various concepts: the selection of 
objects defined by set features, the resulting quantitative data, the chosen feature space (the graphical representational format) and dimension reduction. The first three concepts belong to the harvest/generation of data, the last two to the visual representation of data. The concept of dimension reduction is important; algorithms can easily compute many features, whereas human realisation qua visual representation can only comprehend three dimensions. This is called the "semantic gap" (e.g., Manovich, 2015, p. 22) Hence, visual representation is always a reduction of complexity. Science applies various methods in an attempt to maintain the richness of the data information. Artistic (re)presentations do not have this requirement of a causal correlation between data's informational content and its representation. In this transformational indeterminacy, I claim, lie the artistic and aesthetic possibilities regarding beauty.

\section{Big Data Visualisation as Artistic Challenge}

Precisely this indeterminacy is the starting point of much artistic work dealing with data arrays and the question of signification including layers of signification. In the case of media, Manovich distinguishes between a media artefact (picture, text, sound) and the data that describe the artefact. Regarding pictures, the data would contain the content of the digital parameters digitally describing the picture. A database structured by these kinds of data types occasions very different collections and, thus, very different interpretations than a semantic interpretation of the media artefact proper. On top of that, big data collections are often informed by meta-data about the topics (Manovich, 2012). Meta-data are data about the data, indicating not the media content but, for example, the circumstances of the production and dissemination of the media artefacts. Manovich mentions the example of digital humanities research on the communication between Enlightenment thinkers. This research focuses on "dates, who wrote to whom and their geographical locations." (2012). Jer Thorp's Wired UK 2010 is another good example in that it contains meta-data on quantitatively-defined telephone calls (length and quantity) and no information on the content of the calls whatsoever.

Nonetheless, to be intelligible and imaginable, these types of queries also need some form of visualisation that allows for interpretation and the extraction of sensible information. Visual representations often follow a set of predetermined, prototypical graphic structures such as a tree structure, a globe structure or the radial ordering of data sets (see, for example, http://www.visualcomplexity.com). Thorp's above-mentioned Wired UK 2010, for example, follows a linear representation of (meta)data along $x$ - and $y$-axes. In order to be easily fathomable, visualisations of that kind apply principles of graphic aesthetics that are based on metaphors indispensable for our performative and situated comprehension of the world (see, for example, Johnson and Lakoff's well-known books Metaphors We Live By $(1980,2003)$ and Philosophy in the Flesh (1999)). Graphic forms are embodied metaphors that allow for a situated understanding. For instance, quantitative orderings along two axes 
allow for the comparison of bars that allude to containers or boxes that can contain a certain amount of a given matter. Conversely, the tree structure refers to a series of branches with binary decisions one has to take as one follows along a path. The radial circle, on the other hand, connotes a nucleus, a centralizing force and repetitive cycles around which the onlooker is moving. Cartographic representations, however, are representations of data on the basis of an often 2-dimensional and, therefore, abstract space, which is seen from above, giving a sense of overview by compressing the time needed to travel through the represented landscape. The act of traveling is still immanent in the perception of this type of graphical representation.

As already touched on, artistic data visualisations position themselves in the middle of a cross-field; expressed differently, they serve two masters. On one hand, these visualisations are bound to a scientific ethos that requires data to be the result of accepted and specified methods of data collection and their representation to show a verifiable depiction of the data in terms of information about the object (including event, transformations, etc.) and its contexts (metadata). On the other hand, aesthetic visualisation involves a certain degree of artistic freedom that is not subject to scientific severity but to an artistic rigour. As already mentioned, this distinction between science and art (aesthetics) is historically determined and, thus, not unbridgeable. Is our experience of beauty regarding some data artefacts a token of dissolution of this divide and, thus, of a changed cultural and epistemological context? I am not interested in this question from the viewpoint of science but from the perspective of artistic artefacts. Of interest for me is not what influence aesthetic and artistic dimensions have for presentations of scientific findings (and scientific methods and strategies in the long run--even though this is an interesting question, too, because it is the other side of the coin). Of interest is how data art and data visualisations change our aesthetic perception and understanding of the arts.

As noted, Jer Thorp bases his visualisation in Wired UK 2010 on scientifically accepted models of data representation; however, he develops and alters them towards forms (or creations) that I want to call data figurations. A perceptible and ambiguous yet intelligible figure emerges that, in my opinion, supports Kant's characteristic of aesthetic perception (beauty) as being the result of the interplay between imagination and understanding. Jer Thorp expresses the two sides of his design in the following way on his blog:

I always think of it as needing to serve two separate purposes for two different kinds of readers. First, it needs to be visually pleasing. I want people to say 'Oooh...!' when they turn the page to it. Once they're hooked, though, I want them to learn something - the 'Aaah!' moment. (Thorp, 2010)

He sees the aesthetic dimension as creating attraction to pave the way for a scientific realisation of real world conditions and processes. On the face of it, the visualisation process is, as I have shown, just the opposite. But is the perceptual process that linear, starting with aesthetic pleasure to arrive at some kind of realisation of the data's inherent information 
and potential significances? Or does, on the contrary, the representation of (scientific) data and the integral information change our view and demands concerning aesthetics? Aesthetic dimensions certainly have an influence on epistemology, on how and what we realise (first described in modernity by Baumgarten, 1750/1988). On the other hand, what Thorp perceives as the learning dimension of data visualisation might also change our view of aesthetic artefacts in general. My thesis is, thus, that the sentiment of beauty of data visualisation heralds a change in the epistemological features of aesthetics (concerning artefacts using real life data arrays and feeds). The academic challenge is that the interplay between cognition (comprehension of the information conveyed by data visualisations) and imagination on the basis of sense perception has to be described anew (in comparison to, for example, works of art during romanticism, aestheticism or modern art).

It seems that, until recently, aesthetically interesting imagery had to stimulate our imagination, which is our perceptual capacity to condense sensory information into more or less concrete figurations with the sole purpose of yielding pleasure. This seems to correspond with Kantian beauty, which rejects conceptual dimensions as the foundation of the sentiment of beauty (even though understanding always necessitates concepts). Kantian beauty is not the result of any concept-based realisation but of cognitive play with potential, incipient realisations - and, thus, non-predetermined concepts. Data visualisation, on the contrary, takes concept-based information into the imaginary play of perception. Thorp's data configurations include diagrammatic elements as artistic and perceptual material.

Another example of a data art(efact) is the Project Edison ${ }^{6}$ by IDEO engineers. The artefact is a chandelier comprising a hundred hanging bulbs, each of which can move up and down and dim independently. The chandelier can be animated by many kinds of data - for example, data that describe movement in the hotel lobby in which the piece is installed or data mapping onto a social media site or data related to the weather somewhere in the world as long as the data is parsed into recognisable data formats. The movement and brightness of the bulbs do not establish a denotative sign relation with the data sets employed, but the system transforms the data arrays into dynamic forms applying algorithmically-specified correlations. The sheer dynamics of the chandelier seem to incite our aesthetic, perceptual pleasure. But these dynamics also include a relationship between the original data and their representations. The sheer knowledge of this dependency changes our aesthetic appreciation in that our aesthetic appreciation also entails other epistemological dimensions than the Kantian play of incipient and rudimentary concept formations. What precisely is the intrinsic relationship between the 'ooooh!' and 'aaaah!'?

E. Haeckel's (1904) drawings of natural objects might be seen as a predecessor of this development. The compositional ordering of the species depicted has an immense influence on the perception of the drawings. The figural representations can be seen as figurations that combine or, rather, constantly shift between the aesthetic sentiments of, for example, beauty and the truthful depiction of the species' appearance. Haeckel's drawings 
intertwine, amalgamate and differentiate references to the real and the imaginative and play with multiple understandings.

\title{
Data and the (Anti-)Sublime
}

In contrast to many data visualisation design handbooks, most academic scholars readily associate the aesthetics of data visualisation with the notion of the sublime rather than with beauty. McCosker and Wilken (2014), for example, have published an excellent article on the sublime characteristics of data visualisations in which they state that data visualisation must be understood through Kant's notion of the sublime, especially the mathematical sublime. They write:

\begin{abstract}
Kant is more precise in his notion of the mathematical sublime, which he defines in the Critique of Judgement as the 'estimation of magnitude by means of concepts of number' (2007, sec. 26, 251). Kant' s core argument is that the apprehension of magnitude 'is indeed possible, but not its comprehension in an intuition of the imagination (i.e., it is not possible by means of a comprehensio aesthetica, though quite so by means of a comprehensio logica in a numerical concept)' (2007, sec. 26, 254). (McCosker \& Wilken, 2014, p. 157)
\end{abstract}

As we all know, Kant differentiates between beauty and the sublime. The latter is associated with reason (Germ: Vernunft) and rationality on the basis of a priori laws. Kant never associated the sublime with works of art but primarily with the unimaginable immensity and dynamics of natural phenomena. The aesthetic pleasures of the sublime arise when the onlooker realises and overcomes the menace of the immensity of nature through conceptual a priori ideas (reason) simply because it cannot be imagined and, thus, understood by means of empirical concepts. (Kant, 1799/2008, \$29) The Kantian sublime is one distinct form of aesthetic appreciation.

Philosophical aesthetics and art theory took over the notion of the sublime, allocating it to modern art - especially, abstract art - because, as Lyotard asserts (1984, 1999), modern works of art deal with formlessness and immensity in order to prompt a perceptual shock and "ontological dislocation" (1999, p. 206) that transport the viewer out of the realm of discursive understanding. My assertion, however, is that Lyotard's understanding of the artistic sublime requires a realisation of the underlying artistic idea in order to be aesthetically pleasurable. Furthermore, artistic ideas (also in abstract art and that is what Lyotard writes about) are still expressed through visual media that are compositions of shapes, colours and materialities even if they are intended to present formless immensity. That is why, in recent decades, the sublime aesthetics of abstract art has slowly changed into the aesthetics of beauty simply because our sentiment of beauty has changed to also include artistic concepts. (Heinrich, 2014, chap. 2.6)

One artistic objective of much conceptual and abstract art was to tap into the hidden realm of creation and destruction beyond the human grasp, where artistic forms are 
moulded and demolished. Data visualisation and information art has only recently found its way into the arts and artistic endeavours. Here, the unimaginability of big data arrays seems to replace artistic genius as an ungraspable force that lies outside human volition. However, Lyotard's notion is quite distinct from the alleged sublimity of data visualisation because data always refers to measurable real-world occurrences. I will come back to this.

Mario Costa (1990) applies the sublime to digital artworks, arguing that digital technology construes data systems that, by definition, are formless and unimaginable. Digital art obfuscates and makes altogether obsolete the aesthetic categories of art in modernity (beauty, artist subject, expression, etc., except the (technologically) sublime) because the operationality of this technology positions artist and audience differently than autonomous works of art do - namely, as functions of the artefact's operations. Hence, the artist/ designer and the recipients are integrated, functional parts of the technological artefact. The technological, dynamic sublime operates on the basis of flux and changeability that can only be grasped by means of a conceptual idea - more precisely, by a concept that outlines system-architectonic and functional dimensions through which perceptual manifestations of the technological system are seen.

Warren Sack also associates data aesthetics primarily with the sublime and the "uncanny" (2011, p. 127). Sack asserts that data visualisations and data representation systems must be seen through the lens of concept art in that each representation entails a governing structure, a distinct way of organising data by means of presentation principles. Concept art entails the aesthetics of governance and cybernetics because a conceptual work of art is a description of an action to be undertaken by the recipient more than it manifests the artistic result of actions as an artefact. For Sack, this indicates a shift "from visual aesthetics" to "an aesthetics of governance". Sack's elaborations, however, fail to explain precisely why this is an aesthetic form. He explicitly refers to Baumgarten's original notion of aesthetics as being based on bodily sensation and perception, yet he fails to explain how the aesthetics of governance is linked to the perceiving and thinking human body. My take is that, instead of dismissing beauty as superficial prettiness and simple user-friendliness (Sack, 2011), the conceptual aesthetics of governance should be incorporated into an enhanced notion of beauty, a notion that no longer rejects conceptual (and, thus, discursive) recognitions but combines perceptual imagination and a concept-based understanding, bringing about the sentiment of pleasure.

Today, Kant's analytical distinction between reason and understanding has become increasingly difficult to maintain; hence, the division between beauty and the sublime is on shaking philosophical grounds, too. ${ }^{8}$ I like to think of the beautiful as an immediate pleasure of sense perception and the sublime as a pleasure of ideation connected to the imaginable, as dynamic aspects of aesthetic judgments in which the sublime can be transformed into the pleasures of sense perception and the beautiful can yield ideas related to natural or artistic phenomena. 
Thorp's fairly simple visualisations make apparent principles of ordering and selections, of governance. The onlooker must understand these principles in order to combine the graphic and purely sense-perceptual aspects with the underlying conceptual choices that not only determine the graphic appearance and the depicted imaginary object but also the sense-making process of the represented data. Making sense of the Thorp's graphics influences and guides our experience of aesthetic pleasure in that it adds a sense of a kind of empirical realism.

Another of Thorp's visualisations is even more illustrative of this epistemological relation. Timepiece Graphs is a radial ordering of bars, coloured one way to indicate the use of the word 'hope' and another way to indicate the use of the the term 'crisis' in articles published by the New York Times over a certain timespan. The graphic object alludes to our image of an explosion or a blossoming flower with the word 'crisis' in the middle and 'hope' as the outer rings forming a kind of halo. The superposition of the coloured bars results in a shimmering that emanates a 3-D effect. It is quite evident that Thorp's visualisation does not exclusively follow a scientifically-objective method to represent data as simply and truthfully as possible regarding the resulting data's informational content, method and context of collection. Clearly, the radial ordering adds another level of imaginary that supplements it with a more exciting aesthetic dimension. The crucial thing here is that we can no longer distinguish between purely aesthetic aspects (understood as a pleasurable/ not-pleasurable perception on the basis of purposelessness) and purely scientific aspects (obligated to methodical and representational accuracy).

Does that mean that the notion of beauty is once more synonymous with truth, as many philosophers prior to the Enlightenment claimed? And if so, what kind of truth might that be? An elaboration of this question has to take its beginning in Kant's notion of beauty simply because he is the one philosophical figure who most vehemently claimed and elaborated on the non-conceptual basis of aesthetic judgment, including the perceptual conditions necessary for a pure aesthetic judgment.

\section{Data, Governance and the Question concerning Beauty}

Let me briefly restate that the question of whether an artistic work is beautiful lies at the very heart of our cultural heritage and the expectation with which we approach artistic artefacts. Since modernity, aesthetics was connected with the simple foundational question: do we like an artefact or do we not? Any work of art additionally entails this aspect as our most foundational perceptual expectation.?

Kant's famous elaboration of aesthetic judgment is but one conceptualisation, albeit the most elaborated one. He formulated a concept of beauty that favours an (beautiful) object's formal dimensions in that it is the perception of these formal characteristics that boosts the interplay between imagination (the ability to construct/compress mental 'pictures' either through sense perception or recollections) and the understanding of the 
object's conceptual possibilities. ${ }^{10}$ Practical or conceptual purposiveness does not play a role in pure aesthetic appreciation. According to Kant, only the free play of our perceptual and cognitive capacities without any purpose elicits the pleasurable feeling of pure beauty by which we judge an aesthetic object. However, works of art exist due to human agency and, thus, entail an agential purpose of a kind. To cater to that, Kant proclaims the artist as genius, who is able to transcend the intrinsic purposiveness of human activity. Kantian aesthetics laid the philosophical ground for the autonomy of art as a distinct way of conceiving and perceiving artefacts as works of art.

This can only be done by creating something extra-daily ${ }^{11}$ or framing the quotidian in order to appear extra-daily. The artistic framing is an intrinsic part of any work of art and a precondition for the artifice to be experienced and judged aesthetically (in a Kantian sense). Kant's artistic genius creates art as if it were nature and represents nature as if it were art (Kant, 1799/1957, \$45). In and through an art-creating genius, unfathomable nature reigns and transcends human purpose, conceptuality and teleology (without disposing of them). Kant points at the artistic idea as the locus of genius, an idea that depends on artistic rules (on which any art form must be based), but it transcends these rules in the very act of creation. In this sense, making art and aesthetic appreciation surpass human cognition without rejecting it (Kant, 1799/1957, \$48). What Kant calls beauty is the sensory and perceptual recognition of this excess made manifest in a work of art.

To specify the aforementioned question: Does data art exhibit a similar form of Kantian genius that surpasses human and rule-based creation simply by employing data constellations and fluctuations that, first of all, (re)present measurable factuality and that, second, do this on a macro level surpassing human conceptualization? In order to answer this question, I will have to re-visit concept art and its significance for an understanding of data visualisation and beauty because concept art also tries to externalise artistic variability in that conceptual artworks consist of a concept (an artistic idea) to be unfolded and instantiated either by the artist proper or by the recipient.

Much avant-garde art - especially, concept art and minimal $\operatorname{art}^{12}$ (what Fried terms literal art) - rejected and loathed aesthetic beauty as a normative and qualitative category of visual representation (in terms of, for example, semblance- see, e.g., de Duve, 1997; Danto, 2003). I claim, however, that this ardent rejection of an inherited concept of beauty underlines beauty's importance. There are at least two features of Kant's notion of beauty that play a prominent part in abstract and conceptual art: first, the focus on formal characteristics and, second, the search for artistic endeavours' creative sources. The former is wellknown and written about extensively. Treated less extensively is the relationship between modern art's elaboration of form and the sentiment of beauty. I have already hinted at that; conceptual art's artistic play with form and formal features allows for an adoption of Kantian aesthetics; it is the philosophical basis for an explanation of why modern abstract art can be perceived as beautiful (Heinrich, 2014, pp. 36-42). Kant's promotion of form at the expense of qualia (the agreeable) and conceptually-defined content allows for the purpose- 
less appreciation of art, for the free play of perceptual and cognitive abilities. The formal features sidestep conceptual recognition of finality but not conceptually-based creational play. Modern art's development can be read as a gradual transformation from figurative representation to abstract figuration. It is not a sudden paradigmatic shift that would render probable a categorical change from an aesthetic of beauty to the sublime. Rather, it confuses Kant's two categories by a contemplation and experience of diagrammatic force fields that gradually become non-figural.

As already mentioned, Sack points to the display of governing structures in conceptual art. Sack's explanations tend towards collaborative art practices, which is of no use for my investigation. However, Sack's idea of an aesthetic of governance harbours a shift of focus. Governance could be understood as a means of organising the composition of forms and materials and, as a corollary, as a way of organising the perceivers' perception. Seen in this context, Lyotard's sublime shock must be seen as a token of cultural transformation that also includes the transformation of our notion of beauty. In order to be able to judge conceptual art for its possible beauty, we need to understand the artistic investigation that leads to the singular artwork. In fact, much modern art can be seen as a presentation of the artistic process. Appearance is no longer linked to representation, semblance and expression but to the manifestation of changeability and performance (see also FischerLichte, 2008, chap. 2.1). The resulting work of art is one out of several potential outcomes on the basis of conceptual selections made by the artist. These selections are traced and recapitulated in the act of perception and establish an aesthetic understanding of artistic investigation that might elicit the pleasurable sentiment of beauty. (Heinrich, 2014, p. 39)

Let med analyse the project Weather+ (2015) by Kuan Butts \& Daniel Palencia. It is not an art project, and it is also aesthetically not very successful. Yet, it is an illustrative example. On the face of it, it is conceptually a rather simple website that provides the possibility of visualising various preselected environmental parameters (dust, temperature, humidity, light, sound, and air quality), measured by sensors in different cities around the world (from Shanghai to San Francisco and Rio de Janeiro). The website is divided into two main frames, the right one showing a hexagonal shape, the corners of which indicate the parameters and can be activated by rolling the cursor. The hexagonal figure changes over time depending on the parameters' measured values. The change is shown as traces of previous hexagonal shapes resulting in a palimpsest. On the right hand site, a two-dimensional map of the chosen city is shown containing an indication of the sensor placements. The user's activation of the reactive corners of the hexagram generates superimposed, multi-coloured, round shapes on the map, visualising the values of the measures. The governing strategy regarding the creation and reception processes is fairly transparent in that a clear correlation between the objects and their features, data type and the feature space (the website's interface) and reduction can be experienced. The superimposed shapes, for example, are clearly connected to the placement of the sensors and the colours of these shapes convey the level of the quantitative data as intensity. 
However, the visualisation is rather simple, without any artistic quality; this could have been achieved by composing a visualisation algorithm that transforms measured data into figurations - either abstract or more figurative compositions - that spur the imagination, yet preserve the linkage to the semantic quality of the data. As it is now, the diagrammatic formations still belong very much to the scientific discourse of direct content conveyance but could be developed into imaginative compositions that stand in contrast to the cartographic background and the reactive discourse of the interface (the left part).

\section{Diagrammatic Beauty}

For my argumentation, it is essential to acknowledge that Kant's notion of concept (Ger.: Begriff) differs distinctly from the same term used to explain concept art. Kant's concept points at our cognitive capacity to compress manifold sense data into identifiable phenomena. This necessitates a preformed mental concept of objects, for example. Concept art's notion, on the contrary, refers to an artistic idea as source and artefact alike. The most rigorous instances of concept art consist solely of a description of the action that would lead to a material or performative instantiation of the piece (sometimes, even instantiated by the perceiver). Seen in this light, the two notions of concept indicate almost polar opposites. For Kant, it is the termination of aesthetic imagination; for concept art, it is the very beginning of multiplicity and heterogeneity in potential instantiations and imaginations. That is why Kant's notion of beauty and concept art is not a contradiction but a development. Both seek the perception of a not-yet-finalized understanding: an imagination that plays with potential instantiations, interpretations and significances (see also Guyer, 2005, chap. 3 on the interplay between imagination and understanding). And both seek pleasure in the variability and playfulness of human perception and understanding, but they use different paths and different visual outcomes.

In order to accommodate this, they need a means that transcends human determinacy - namely, the human inclination to finalise perception and significance into recognisable objects. As already mentioned, Kant introduces the genius artist, who move beyond perceptual, cognitive and artistic rules, thereby opening a space of unanticipated potentiality. Concept art has tried to overcome human determinacy, for example, by introducing a difference and incommensurability between artistic idea and actual realisation. In both cases, Deleuze's understanding of the diagram is interesting - not because it describes certain graphic elements but, rather, because he sees the diagram as a vital operative set that eventually leads to (or discomposes) figuration of a kind. He writes, "[t]he diagram is thus the operative set of signifying and nonrepresentative lines and zones, line-strokes and colour-patches" (Deleuze, 2005, p. 71). For Deleuze, diagrams are not representations of data or thinking patterns but operational forces that bring about figuration of any kind, be it pictorial, painterly figuration or an abstract constellation (that, according to Deleuze, becomes a "symbolic code"). "The diagram is indeed a chaos, a catastrophe but it is also a 
germ of order and rhythm" (p. 102). It is tightly linked to physics and physical actions and only subsequently to conceptual ordering. Diagrams come to the fore in the very act of creation, in the interstices between preparation (in my understanding, the initiating concept or artistic idea) and the physical, bodily act of materialisation and instantiation. DeLanda explains the well-known Deleuzian take on material reality's inherent nature of differences and heterogeneity: "But as Deleuze argues, the role [...] of the diagrammatic and problematic nature of reality, can only be grasped during the process of morphogenesis, that is, before the final form is actualized, before the difference disappears" (DeLanda, 2000, p. 36). Massumi interprets Deleuze's diagram as a graph that entails and makes visible (and sensory) various dynamic interrelations: "as a genesis in a state of things [...] and again in ideality (concept to concept). The diagram combines the past and the future of the past [...] " (Massumi, 1992, p. 16). He gives words to both the material generative process and the conceptual indeterminacy that precedes and follows any manifestation. He sums up: "Any sign, quality, or statement, as the trace of a process of becoming, can be considered a de facto diagram from which a formal diagram of the operative abstract machine could be developed" (Massumi, 1992, p. 17).

This, of course, is quite different from the scientific use of the notion. McCosker and Wilken (2014) also mention the dual usage of the term diagram, first, as a representational means of complex data, by "bring[ing] about forms able to represent relations, express quantities, and ultimately draw out inferences with the maximum of visual clarity. Clarity of visualisation is equated with clarity of (statistical) thinking" (McCosker \& Wilken, 2014 (referring to Tufte, 1997)) and, second, as a generative machine. This Deleuzian morphogenetic machine complicates information conveyance by exposing not only the diagram's dependency on information from both the designer/artist and the data sets available but also by elevating the diagram to a fundamental structuring force. Besides being "abstract graphic portrayals of the subject matter they represent" (Lowe, 1993), they are, first of all, operating programs (machines) that generate and create realities as interplay between data, the human artist and graphic possibilities.

Following Massumi, these two, in scope and modality, appear to be very different descriptions of the diagram, but are merely two dimensions of the same process. At least in the case of artistic data visualisation and, according to Deleuze, visual art in general, both dimensions can be used as either synthetic-productive or analytical tools.

Data art presents itself as comprised of abstract, potentially dynamic formations that translate and, thus, describe occurrences external to the artefact. On the face of it, there is no direct material or iconic relationship but an indexical one. Seen from the perspective of the artist/designer, however, the mapping process always contains a dual transformation: He or she has to think as a scientist in order to create a translation program (or, in Deleuzian terms, a machine) that establishes an identifiable linkage between the informational content of the chosen data and the graph. The artist/designer takes on the position of a commentator on data by creating diagrams that allow for the amalgamation of concep- 
tual and perceptual inferences of various kinds. These interferences point to another level because the diagrammatic mechanism overrides mere scientific commentary and enters the realm of creation that incorporates heterogeneous elements into an imaginary mix of information, traced data variations and dynamics, references to factual incidents, analytical inferences, emerging mental and visual objects, etc.

My last example is Lev Manovich's data visualisation of art historical data (depicted and described in his above-mentioned article from 2015). The data source is 200 features of 6000 French impressionist paintings. The visualisation consists of tiny rectangular representations of the actual paintings ordered in a 3-D space according to an algorithmic method (principle component analysis) that reduces these many dimensions (features) to an imaginable gestalt in space, grouping together paintings that encompass similar features. The visual result is an almost floating, transient formation that appears to be on the verge of transformation. There is no figurative beauty in the visualisation, but there is an enticing presentation of dynamicity and transformability contained in the visualisation that is both beautiful and sublime: beautiful in the tranquility of the presentation and sublime in the experience of changeability. The sublime emerges in the realisation of the unfathomable complexity, the beautiful in the reduction of this complexity into an imaginable gestalt. The oscillation between these two modes of perception constitutes and is constituted by the diagrammatic vectors that underlie the visualisation.

\section{Conclusion}

In 2001, I visited Peter Greenaway's exhibition Flying Over Water (2001) at Malmø Konsthall. The exhibition consisted of a huge variety of different objects, all associated in one way or another with flying and with Icarus's flight and fall. The exhibition was very scientific; it collected, ordered and displayed objects as diverse as feathers, wax, remains of the meal Daedalus might have eaten while building the flying machine, construction plans, bird wings and skeletons, water samples and an artificial heart--diversity united by a chosen theme's associative possibilities. "In Flying Over Water, religion, myth, natural science, technology and an erratic world's inventory are entangled in a natural alliance" (afsnitP, 2001, my translation $\left.^{13}\right)$. On the face of it, this exhibit mimicked a forgotten room in a, perhaps, outdated science museum filled with objects and relics, almost like the Athanasius Kircher Museum (Museanum Kircherianum). The objects' inherent facticity and reality are intertwined with and contested by imaginations and associations. The entire exhibit is a diagram in Deleuze's sense - simultaneously, a space and a machine that, in its sheer extent, disturbs and eventually surpasses human intentionality.

Data visualisation has similarities to this curatorial praxis. The curator-artist and the data visualisation artist have become quasi-scientists (and some scientists have become viz artists ${ }^{14}$ ) who construct visual and exhibition programmes that perceptually guide the onlooker towards the formation of acts by oscillating between formal reflection and 
aesthetic imagination. The alleged unpredictability and unfathomability of big data (the sublime aspect) is employed to transgress human intentionality and cognitive mannerism. Thus, data is more than a positivist undercurrent of data art; it is also an artistic means aimed at the virtualisation of the concreteness of lines and colours and, by the same token, of the factuality of data proper.

Jer Thorp's Timepiece Graphs mimics a star or explosion and refers to quantitative measurements of word usage. The perceptual challenge is to combine sense-making through the act of referencing with imagination. Tatiana Plakhova's work alludes to some sort of jellyfish or other organic creature that gives assemblies of traced online connections a transient shape that, in turn, adds images to otherwise dry data. The D-Tower in Doetinchem, which lights up at night in different colours that symbolically show the emotions of selected parts of the city, takes the shape of some kind of organic creature. The emotional state of a city area has found a not-fully-determined shape, leaving space for interplay between understanding and imagination. Clearly, these pieces can be perceived as and judged for their sculptural or figurative dimension alone. But the enticing aspect is the unresolved interplay and juxtaposition between artistic figuration and data flux.

\section{Noter}

1 It is far from clear, however, whether these pieces actually deploy the amount and complexity of data necessary legitimately to be called big data art.

2 The framing consists of the presentation of the work as a unified artefact that marks a distinction between the artefact and the rest. That does not mean that the artefact is a solipsistic entity without references or other forms of relation to its societal, personal, political and psychological surroundings.

3 In particular, the aestheticism of Romanticism exerted an opposition (and a compensation) to the thenprevailing rationalism of science in emphasising emotionality, intuition and humour.

4 Although the sentiment of beauty appears to be fairly stable, expressing itself as pleasure (e.g., Hutcheson, Hume, Kant), only modernity has defined beauty in terms of a sentiment and no longer as a metaphysical idea represented by formal characteristics of artefacts. In addition, metaphysical ideas yield a psychophysiological reaction, but only modernity has defined beauty in terms of subjective pleasure. Furthermore, the object of beauty changes historically, depending on art's societal and personal function and value.

5 Since then, the notion of sensus communis has swung back and forth between, on the one side, being historically-culturally determined values and, on the other side, being transcendental values within the functionality of human perception and cognition (see, for example, Kester, 2004/2013). For me, this is not necessarily a contradiction, because the modern (Kantian) understanding of transcendentality yields values such as freedom of perception and interpretation, creativity and also playability, all values associated with art in modernity and, in particular, modern art.

6 For a description, see: http://www.wired.com/2014/04/a-high-tech-chandelier-that-visualizes-anydata-stream-you-like/\#slide-id-800151 (last retrieved Jan. 2015)

7 Other interactive chandeliers work with more denotative visualisations/animations. Studio Soso Limited's chandelier, for example, shows conflict zones as part represented and animated geographical maps 
(continent or countries). http://www.gizmodo.com.au/2014/01/this-interactive-chandelier-shineswith-data-from-all-over-the-world/ (retrieved, Jan 2015).

8 For a more lengthy elaboration on the interdependence of the Kantian concepts of the beautiful and the sublime, see Heinrich, 2014. Recent neuroscience makes plausible that the relationship between cognition (e.g., ideation) and sense perception is complex and not linear. Ideas and cultural concepts influence sense perception and vice versa (see, for example, Varela, 1993; Damasio, 1994; and McMahon, 2007)

9 That is not to say that beauty can be exclusively found in the arts - far from it - or that art in modernity exclusively deals with beauty - not at all.

10 Kant focuses on the formal characteristics of an object of beauty and not on content of any kind; this points to a notion of understanding on the basis of concepts (German: Begriff) and not on, for example, the colour that stimulated the sentiment of agreeability in yielding corporeal gratification or moral values. Only the focus on form secures the free interplay of imagination and understanding eliciting unbound pleasure. Paradoxically, much modern art, while rejecting the importance of beauty, focuses on the means and materials of art, including form and composition. Thus, much modern art is in accordance with Kant's plea even though it rejects the representational, mimetic paradigm paramount at Kant's time.

11 Extra-daily is a term theatre director Eugenio Barba uses in order to specify the actors' not-quotidian way of using the body. This concept can also be applied to other art forms.

12 My descriptions of conceptual art (including minimal art) can be but bold generalisations of certain aspects. Clearly, the sheer variety of modern works of art shows a huge span of different characteristics and ambitions. My elaborations pick specific traits and treat them in a very general manner. The scope and length of this article do not allow for a more case-specific treatment.

13 "I Flyga över vatten er religion, myte, naturvidenskab, teknik og den tilfældige verdens inventar filtret sammen i en selvfølgelig alliance."

14 See, for example, Ambrosia, 2015), "Objectivity and Representative Practices across Artistic and Scientific Visualizations".

\section{References}

afsnitP (2001). Fra dinosaur til kolobri (og omvendt og omvendt og omvendt), http://www.afsnitp.dk/ aktuelt/aktueltarkiv/5/fradinosaurtilko.html, last retrieved, Jan. 2015.

Ambrosia, C. (2015). Objectivity and representative practices across artistic and scientific visualizations in A. Carusi et al. (Eds.), Visualization in the Age of Computerization. New York: Routledge.

Baumgarten, A. (1750/1988). Theoretische Ästhetik - Die grundlegenden Abschnitte aus der "Aesthetica". Hamburg: Felix Meiner Verlag

Boyd, D. and K. Crawford. (2012). Critical questions for big data. Information, Communication \& Society, 15 (5), 662-679.

Bürger, P. (1984). The Theory of the Avantgarde. University of Minnesota Press.

Burnham, J. (1968). Beyond Modern Sculpture. New York: George Braziller, Inc.

Costas, M. (1990). Il sublime tecnologico. Salerno: Edisud

Damasio, A. (1994). Descartes' Error. New York: Quill

Danto, A. (2003). The Abuse of Beauty. Peru, Illinois: Open Court

de Duve, T. (1997). Kant after Duchamp. Cambridge: MIT Press.

De Landa, M. (2000). Deleuze, diagrams, and the genesis of FormAuthor(s)". American Studies, 45, 1, Chaos/ Control: Complexity, 33-41. http://www.jstor.org/stable/41157534. Accessed: Jan. 2015. 
Deleuze, G. (2005). Francis Bacon. London: Continuum Books.

Fischer-Lichte, E. (2008). Transformative Power of Performance: A New Aesthetics. New York: Routledge. Guyer, P. (2005). Values of Beauty - Historical Essays in Aesthetics. New York: Cambridge University Press. Haeckel, E. (1904). Kunstformen der Natur. https://archive.org/details/kunstformenderna00haec (last retrieved, Jan. 2015).

Heidegger, M. (1993). The origin of the work of art. Basic Writings. London: Routledge.

Heinrich, F. (2014). Performing Beauty in Participatory Art and Culture. New York: Routledge.

Hume, D. (1757/2008). Of the Standard of Taste. In S. Copley and A. Edgar. (Eds.), Selected Essays, 133-154. Oxford: Oxford Paperbacks.

Kant, I. (1764/2011). Observation on the Feeling of the Beautiful and the Sublime. Cambridge: Cambridge University Press.

Kant, l., 1799/2008. Critique of Judgment. Oxford: Oxford World's Classic.

Kester, G. (2004/2013). Conversation Pieces - Community and Communication in Modern Art. Berkeley, Los Angeles: University of California Press.

Lakoff, G. and Johnson, M. (1980, 2003). Metaphors We Live By. Chicago: The University of Chicago Press.

Lakoff, G. and Johnson, M. (1999). Philosophy in the Flesh. New York: Basic Books.

Laney, D. The importance of 'big data': A definition. https://www.gartner.com/doc/2057415/importancebig-data-definition (last retrieved Jan. 2015).

Lowe, R. (1993). Diagrammatic information: techniques for exploring its mental representation and processing. Information Design Journal, 7, 3-18.

Lyotard, J.-F. (1999). The Sublime and the Avant-Garde. In A. Benjamin. (Ed.), The Lyotard Reader. Cambridge: Basil Blackwell.

Lyotard, J.-F. (1999). Newman: The instant. In A. Benjamin (Ed.), The Lyotard Reader. Cambridge: Basil Blackwell, 240-249.

Lyotard, J.-F. (1984). The Postmodern Condition: A Report on Knowledge. Manchester: Manchester University Press.

Manovich, L. (2002). The anti-sublime ideal in data art. http://virus.meetopia.net/pdf-ps_db/LManovich_ data_art.pdf (retrieved Jan. 2015).

Manovich, L. (2012). Museums without walls, art history without names. In C. Vernallis (Ed.), Oxford Handbook of Sound and Image in Digital Media. Oxford: Oxford University Press.

Manovich, L. (2015). Data science and digital art history. In International Journal for Digital Art History. München: Graphenties Verlag.

Massumi, B. (1992). A User's Guide to Capitalism and Schizophrenia: Deviations from Deleuze and Guattari. Boston MA: MIT Press.

McCosker, A., \& Wilken, R. Rethinking 'big data' as visual knowledge: The sublime and the diagrammatic in data visualization. Visual Studies 29, 2, 155-164.

McMahon, J. (2007). Aesthetics and Material Beauty. New York: Routledge

Sack, W. (2011). Aesthetics of information visualization. In M. Lovejoy et al. (Eds.), Context Providers: Conditions of Meaning in Media Arts. Bristol: Intellect.

Sartwell, C. (2004). Six Names of Beauty. London, New York: Routledge.

Segaran, T., \& Hammerbacher, J. (2009). Beautiful Data: The Stories Behind Elegant Data Solutions. O'Reilly Media.

Snijders, C., Matzat, U., \& Reips, U.-D. (2012). 'Big Data': Big gaps of knowledge in the field of Internet. International Journal of Internet Science, 7, 1-5.

Steele, J., \& Iliinsky, N. (Eds.). (2010). Beautiful Visualization Looking at Data through the Eyes of Experts. Sebastopol (CA): O'Reilly Media, Inc. 
Article: (Big) Data, Diagram Aesthetics and the Question of Beauty

Stendhal (Beyle, M.-H.) (1980). De l'amour, coll. «Folio» 357. Paris: Gallimard.

Varela, F., Thompson, E., \& Rosch, E. (1993). The Embodied Mind - Cognitive Science and Human Experience. Boston: MIT Press.

Whitehead, A. (1933/1969). Adventures of Ideas. New York: The Macmillan Company.

\section{Artworks}

Thorp, Jer, 2010. Wired UK.

Plakhova, Tatiana, 2009. Jellyfish.

Hershman, Lynn, 2000-02. Synthia Stock Ticker.

Hansen, Mark and Rubin, Ben, 2003. Listening Post.

Serafijn, Q.S. and Spuybroek, Lars/NOX-Architekten, 2003. D-Tower.

Komar, Vitaly and Melamid, Alexander, 1994-97. The Most Wanted Painting.

Rokeby, David, 2002. Taken.

Sester, Marie, 2003. Access.

IDEO, Project Edison (http://www.wired.com/2014/04/a-high-tech-chandelier-that-visualizes-anydata-stream-you-like/\#slide-id-800151).

Mora, F. L., 1905. The Artist in His Studio.

Falk Heinrich

Associate Professor, PhD.

Head of Studies, School of Communication, Art and Technology

Department of Communication and Psychology

Aalborg University

falk@hum.aau.dk 